\title{
Aislamiento de Salmonella spp. en heces de fauna urbana en un parque recreativo de Quito
}

Prevalence of Salmonella spp. in canine and domestic pigeon feces in "La Carolina" park

\section{Cangui Panchi S. ${ }^{1 *}$; Delgado Juca ${ }^{1}$ K.; Terán Soto R. ${ }^{1}$; Echeverría Llumipanta I. ${ }^{1}$; Tapia Calvopiña $\mathbf{I}^{1}{ }^{1}$}

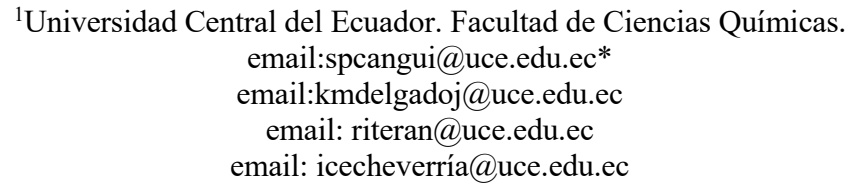

\author{
Articulo original \\ Recibido: febrero 2021 \\ DOI: https://doi.org/10.29166/quimica. \\ v7i1.2921 \\ Publicado: abril 2021
}

Resumen: La zoonosis es considerada un problema de salud pública a nivel mundial y una de las enfermedades con mayor incidencia es la salmonelosis ya que el microorganismo sobrevive a condiciones ambientales extremas y por su fácil transmisión mediante el contacto directo con animales y alimentos contaminados con materia fecal. Los reservorios zoonóticos más importantes son los perros (Canis lupus familiaris) y las palomas domésticas (Columba livia) por su cercana convivencia con el ser humano y porque excretan el patógeno hasta tres meses posteriores a la infección. El objetivo de la investigación fue determinar la prevalencia de Salmonella spp. en heces caninas y de paloma doméstica en el Parque "La Carolina". Se recolectaron 100 muestras de heces de cada animal anotando las características macroscópicas más relevantes seguido de un análisis microbiológico adecuado. Los resultados mostraron una prevalencia del 3\% en heces caninas y 5\% en heces de paloma doméstica. El análisis estadístico de las características macroscópicas como factor de riesgo en la determinación de Salmonella spp. no tiene una correlación significativa. Se concluye que la existencia del microorganismo en la materia fecal de ambos reservorios zoonóticos representa el primer paso para determinar un problema de salud pública. Por ello, posteriormente es necesario analizar que serovariedades fueron encontradas en este estudio y profundizar en que grado afectan la salud del ser humano, ya que este patógeno es eliminado y diseminado con facilidad.

Palabras clave: Zoonosis, Salmonella spp., Heces, Perros, Palomas domésticas

Abstract: Zoonosis is considered a public health problem worldwide and one of the diseases with the highest incidence is salmonellosis because the micro-organism survives extreme environmental conditions and because of its easy transmission through direct contact with animals and food contaminated with faecal matter. The most important zoonotic reservoirs are dogs (Canis lupus familiaris) and domestic pigeons (Columba livia) because of their close cohabitation with humans 
and because they excrete the pathogen up to three months after infection. The aim of the research was to determine the prevalence of Salmonella spp. in canine and domestic pigeon faeces in "La Carolina" Park. A total of 100 faecal samples were collected from each animal, noting the most relevant macroscopic characteristics followed by an appropriate microbiological analysis. The results showed a prevalence of 3\% in canine faeces and 5\% in domestic pigeon faeces. Statistical analysis of macroscopic characteristics as a risk factor in the determination of Salmonella spp. has no significant correlation. It is concluded that the existence of the microorganism in the fecal matter of both zoonotic reservoirs represents the first step to determine a public health problem. Therefore, later it is necessary to analyze which serovars were found in this study and to delve into the degree to which they affect human health, since this pathogen is easily eliminated and spread.

Key Words: Zoonosis, Salmonella spp., Feces, Dogs, Domestic pigeons

\section{Introducción}

La Organización Mundial de la Salud (OMS) define a las enfermedades zoonóticas como un grupo de infecciones transmitidas de animales a seres humanos debido su contacto directo e indirecto, a través de mordeduras, arañazos, saliva, caspa y especialmente por el contacto con sus excrementos (1). Las zoonosis se consideran un problema de salud a nivel mundial, ya que han provocado 600 millones de casos de enfermedades y 420000 muertes en el año 2015 (2).

Según la Organización Panamericana de la Salud (OPS) de los 1415 patógenos humanos conocidos en el mundo, 61\% son zoonóticos (3). En Ecuador se ha registrado que el $80 \%$ de patologías infecciosas están relacionadas con el contacto cercano entre animales y humanos, principalmente con la materia fecal (4). La materia fecal animal puede transmitir virus, bacterias, hongos $\mathrm{y}$ protozoos (5). Dentro de las bacterias que han sido aisladas con mayor importancia en lugares públicos destaca Salmonella que es causante de la infección conocida como salmonelosis (6).
La sintomatología ocasionada por Salmonella enteritidis en los humanos cursa con fiebre, diarrea, vómitos, cólico abdominal, malestar general y escalofríos (7). Los dos principales modos de transmisión de Salmonella spp. según la OMS son el consumo de alimentos contaminados con materia fecal y el contacto directo con los animales (1).

Los parques y plazas de muchas ciudades tienen un alto tránsito de personas y muchas de ellas, se dedican a la venta y preparación de comida ambulante. Esto implica la presencia de animales cuyos desechos biológicos como las heces fecales podrían diseminarse y llegar a contaminar el suelo, agua y alimentos consumidos por la población. Las autoridades sanitarias constantemente buscan controlar la presencia de la fauna urbana en estos sitios, sin llegar a darse una solución efectiva (9)(10). Se ha calculado que alrededor de 5566 a 6 350 perros que deambulan libremente en las calles de todo el Distrito Metropolitano de Quito (11) y se ha registrado que en el centro histórico de esta misma ciudad viven aproximadamente 2000 palomas domésticas en constante movimiento (12). 
Los perros y las palomas domésticas son muy cercanos al ser humano y constituyen los mayores reservorios de Salmonella spp., además, este microorganismo puede sobrevivir durante un tiempo prolongado en las heces debido a que desarrolla ciertas capacidades bacterianas para soportar los cambios drásticos de $\mathrm{pH}$, mantener una elevada adhesión a las células intestinales del humano o de otro animal, conservar una alta competencia para sobrevivir al antagonismo de la flora intestinal, penetrar en los tejidos sin dificultad y producir toxinas (exotoxinas o endotoxinas) (8).

Los perros pueden transportar este patógeno de forma asintomática o sintomática, pero con desprendimiento intermitente, incluso algunos serovares de Salmonella spp. pueden adaptarse genómicamente para sobrevivir en esta especie hospedadora (11). Por otro lado, la paloma doméstica es potencialmente zoonótica, ya que su materia fecal se dispersa con mucha facilidad en el ambiente contaminando alimentos y agua (5).

El objetivo de esta investigación fue determinar la prevalencia de Salmonella spp. en heces caninas y de paloma doméstica recolectadas en el Parque "La Carolina” del Distrito Metropolitano de Quito, un sitio altamente concurrido de la ciudad, donde la venta y preparación de comida ha aumentado drásticamente debido a la migración y donde la presencia de perros y palomas es constante.

\section{Parte experimental}

\subsection{Materiales y reactivos}

Debe describirse la calidad, pureza, origen de los reactivos, materiales y equipos utilizados en la investigación. Como medios de cultivos se emplearon: Agua Peptonada Tamponada CONDA Agua Peptonada Tamponada CONDA, Caldo Rappaport Vassiliadis CONDA, Agar XLD
DIFCO, Agar TSA HIMEDIA, Agar TSI HIMEDIA, Agar LIA CONDA, Agar Simmons Citrato DIFCO, Agar Urea MERCK, Agar MIO CONDA, Agar Fenilalanina Desaminasa CONDA y Caldo BHI CONDA.

\subsection{Diseño y muestra}

Debido a la falta de registros o bases de datos que indiquen una población exacta de perros y palomas domésticas existentes en el lugar del muestreo, este estudio no posee un marco muestral, por lo que para el cálculo del tamaño de muestra se utiliza la fórmula que considera a la población como infinita o desconocida:

$$
n=\frac{Z^{2} x p \times q}{e^{2}}
$$

Donde:

- $n=$ tamaño de muestra

- $\quad Z=$ valor de estandarización que indica el nivel de confianza (constante 1,96 para el $95 \%$ de representatividad)

- $e=$ límite error muestral $(10 \%=0,1)$

- $\quad p=$ probabilidad a favor $(0,5)$

- $q=$ probabilidad en contra $(0,5)$

$$
n=\frac{(1,96)^{2} x(0,5) x(0,5)}{(0,1)^{2}}=96,04
$$

Por lo tanto, se recolectaron 100 muestras de heces caninas y 100 de heces de palomas domésticas tanto frescas como secas. Las muestras secas se incluyeron en el estudio para conocer si a pesar de la influencia de las condiciones ambientales y de la microbiota del entorno aún era posible aislar Salmonella y también porque la materia fecal en estas condiciones tiene mayor facilidad de dispersarse en el ambiente y contaminar distintas áreas entre las que se puede considerar los lugares 
donde se expenden alimentos, lo que podría sugerir la evidencia de ser un potencial riesgo para la salud.

Las muestras fueron recolectadas en envases estériles y se mantuvieron entre 2 a $8^{\circ} \mathrm{C}$ previo a su procesamiento en el laboratorio de Microbiología de la Facultad de Ciencias Químicas de la Universidad Central del Ecuador. El período de muestreo fue los domingos desde el 29 de Julio hasta el 2 septiembre del año 2018. El parque se dividió en 7 zonas para la recolección de las muestras de heces: jardín botánico ( 9 muestras de heces de perro, 11 de paloma), pista atlética (13 muestras de heces de perros, 18 de paloma), juegos infantiles (30 muestras de heces de perro,16 de paloma), zona canina ( 7 muestras de heces de perro, 1 de paloma), laguna "El Quinde" (10 muestras de heces de perros, 27 de paloma), pista de ciclismo (10 muestras de heces de perro, 9 de paloma) y canchas (21 muestras de heces de perros, 18 de paloma). Se registraron características como: tipo y consistencia de todas las muestras.

\subsection{Detección de Salmonella en heces}

Se siguió la metodología descrita en "Manual para la Vigilancia, Prevención y Control Sanitario de Agentes Zoonóticos y Zoonosis relacionada a la Paloma Doméstica" del Ministerio de Salud de Perú (13) y en el caso de los perros se aplicó el "Instructivo Técnico para la Detección de Salmonella spp" según la norma ISO 6579:2002 (14). Luego, se pesó 1 gramo de cada una de las muestras de heces de perros y de palomas, luego se colocó en un tubo contenía $9 \mathrm{ml}$ de medio de preenriquecimiento Agua de Peptona Tamponada y se incubó a $37^{\circ} \mathrm{C}$ por aproximadamente $24 \mathrm{~h}$. A continuación, se tomó $1 \mathrm{~mL}$ del caldo y se subcultivó en Rappaport-Vassiliadis que se incubó a $41.5^{\circ} \mathrm{C}$ por un período de entre 18 y $24 \mathrm{~h}$. Después se sembró en agar Xilosa Lisina Desoxicolato (XLD) que se incubó por 24 a $48 \mathrm{~h}$ a $37^{\circ} \mathrm{C}$. Las colonias sospechosas de Salmonella spp. (centros de color negro y colonias transparentes) se aislaron y criocongelaron para su posterior identificación.

\subsection{Identificación de bacterias aisladas}

Las bacterias fueron identificadas por pruebas bioquímicas como: LIA (desarboxilación de la lisina), TSI (fermentación y producción de sulfuro hidrógeno y gas), Simmon Citrato, MIO (descarboxilación de la ornitina para la producción de indol y movilidad bacteriana), Urea (enzima ureasa) y Fenilalanina descarboxilasa (desaminación de la fenilalanina) (13) (14).

\subsection{Análisis de Datos}

Para realizar el análisis estadístico, todos los datos fueron trasladados a una base de datos en Microsoft Office Excel 2016 y se transfirieron al programa informático Software SPSS versión 2.0, también se utilizó el programa bioinformático WinEpi Working in Epidemiology de la Universidad de Zaragoza de la Facultad de Veterinaria (www.winepi.net). Todos estos programas ayudaron al análisis descriptivo de los resultados para finalmente establecer la prevalencia de Salmonella spp. en las muestras de materia fecal canina y de paloma doméstica, haciendo uso de cálculos estadísticos como: porcentajes, frecuencias, rangos de prevalencia real, Chi2 de Pearson, Chi2 con corrección de Yates, test exacto de Fisher, Odds Ratios (OR) e intervalos de confianza.

\section{Resultados}

En la Tabla 1 se presentan las bacterias aisladas en la materia fecal de ambos agentes zoonóticos. Se 
aisló en mayor porcentaje cepas de Enterobacter aerogenes ( $43 \%$ en heces de perros y $48 \%$ en palomas) seguido de Escherichia coli (35\% en heces de perros y $40 \%$ en palomas) y con menor frecuencia otros agentes microbianos como Proteus spp. (12\% en heces de perros y $1 \%$ en palomas), Klebsiella pneumoniae ( $6 \%$ en heces de perros y $4 \%$ en palomas), Shigella spp. (5\% en heces de perros y palomas), Serratia marcenses ( $1 \%$ en perros) y Salmonella spp. (3\% en heces de perros y $5 \%$ en palomas). El análisis estadístico realizado mediante el programa bioinformático indica que el rango de prevalencia real de Salmonella en heces de perros es de $0-6 \%$ y para las palomas es de $1-9 \%$.

Tabla 1. Bacterias aisladas de las muestras de heces de perros y palomas

\begin{tabular}{|c|c|c|c|c|}
\hline \multirow[b]{2}{*}{ Bacterias } & \multicolumn{2}{|c|}{$\begin{array}{l}\text { Perros } \\
(\mathrm{N}=100)\end{array}$} & \multicolumn{2}{|c|}{$\begin{array}{l}\text { Palomas } \\
(\mathrm{N}=100)\end{array}$} \\
\hline & $\begin{array}{l}\text { MP } \\
(\%)\end{array}$ & $\begin{array}{c}\text { IC } \\
95 \%\end{array}$ & $\begin{array}{l}\text { MP } \\
(\%)\end{array}$ & $\begin{array}{c}\text { IC } \\
95 \%\end{array}$ \\
\hline $\begin{array}{c}\text { Salmonella } \\
\text { spp. }\end{array}$ & 3 & $\begin{array}{c}0,14- \\
2,52\end{array}$ & 5 & $\begin{array}{c}0,40- \\
7,32\end{array}$ \\
\hline $\begin{array}{c}\text { Enterobacter } \\
\text { aerogenes }\end{array}$ & 43 & $\begin{array}{c}0,47- \\
1,43\end{array}$ & 48 & $\begin{array}{c}0,70- \\
2,20\end{array}$ \\
\hline $\begin{array}{c}\text { Escherichia } \\
\text { coli }\end{array}$ & 35 & $\begin{array}{c}0,45- \\
1,43\end{array}$ & 40 & $\begin{array}{c}0,70- \\
2,13\end{array}$ \\
\hline $\begin{array}{c}\text { Klebsiella } \\
\text { pneumoniae }\end{array}$ & 6 & $\begin{array}{c}0,42- \\
5,57\end{array}$ & 4 & $\begin{array}{c}0,18- \\
2,38\end{array}$ \\
\hline Shigella spp. & 5 & $\begin{array}{c}0,28- \\
3,57\end{array}$ & 5 & $\begin{array}{c}0,28- \\
3,57\end{array}$ \\
\hline $\begin{array}{c}\text { Serratia } \\
\text { marcences }\end{array}$ & 1 & - & 0 & - \\
\hline Proteus spp. & 12 & $\begin{array}{l}1,72- \\
15,93\end{array}$ & 1 & $\begin{array}{c}0,01- \\
0,58\end{array}$ \\
\hline
\end{tabular}

MP: muestras positivas

El análisis estadístico comparativo entre los dos grupos investigados; es decir, perros y palomas domésticas y la variable de prevalencia indican que el 5\% encontrado en las heces de palomas domésticas tiene una estimación de riesgo $\mathrm{OR}=$ 1,70 ; por lo tanto, es 1,70 veces más probable que se encuentre Salmonella spp. en heces de paloma doméstica que en heces de perros, aunque estos resultados no son estadísticamente significativos por la mínima diferencia encontrada entre los reservorios zoonóticos, lo que sugiere que tanto las heces de perros como las de palomas pueden contener Salmonella spp.

Las muestras positivas para Salmonella spp. fueron aisladas en diferentes zonas del parque: canchas $4,8 \%$, juegos infantiles 3,3\% y pista atlética $7,7 \%$ en las heces caninas; juegos infantiles 6,3\%, laguna "El Quinde" 7,4\%, pista atlética 5,6\% y pista de ciclismo $11,1 \%$ en las heces de paloma doméstica.

El análisis estadístico de las características macroscópicas se realizó para evaluar los posibles factores de riesgo existentes en las muestras de heces que puedan indicar que los perros o las palomas domésticas tengan salmonelosis. Según el tipo de muestra, en la materia fecal canina seca se cuantificó una prevalencia de 2/53 (3,77\%) con un $\mathrm{OR}=2,13(\mathrm{IC} 95 \%=0,19-24,25)$, por otro lado, en las heces secas de paloma doméstica indicaron una prevalencia de $3 / 59(5,08 \%)$ con un $\mathrm{OR}=2,25$ (IC 95\% = 0,36-14,11). Asimismo, se registró la consistencia de la materia fecal canina que contenía Salmonella spp. que fue únicamente firme $3 / 62(4,83 \%)$, mientras que en la materia fecal de la paloma doméstica se aisló esta bacteria con mayor frecuencia en heces blandas 2/26 (7,69\%) con un $\mathrm{OR}=1,97$ (IC 95\% $=0,31-12,52$ ). Los resultados obtenidos no son estadísticamente significativos, por lo que no se puede establecer una relación entre las características 
macroscópicas y la presencia de Salmonella spp. en las heces de perros y palomas domésticas.

\section{Discusiones y conclusiones}

La prevalencia de Salmonella en la materia fecal de los perros en nuestro estudio fue del $3 \%$ y en palomas del 5\%. Otros estudios reportan porcentajes mayores en heces de perros, como el de Amadi et al., donde analizaron 144 muestras de heces no diarreicas de perros callejeros y aislaron el 5,6\% en seis parroquias de la isla de Granada entre los meses de agosto y octubre del 2016 (15). El aislamiento del 5\% en la materia fecal de paloma doméstica (Columbia livia) concuerda con el estudio realizado en Sorocaba, Brasil en el período de noviembre 2014 a marzo 2015, donde se reportó una prevalencia del 4,23\% de un total de 118 muestras (18). Resultados similares se obtuvieron en el estudio de Gong et al., donde se describe una prevalencia similar de positividad igual a $4,1 \%$ (19). Por otro lado, en una investigación realizada en Egipto se reportó una prevalencia más alta del $13,3 \%$ (6/45) durante un período de 12 meses entre 2010 - 2011, con el análisis de hisopos rectales de muestras frescas (20). Los hallazgos en este último estudio pueden atribuirse a la diferencia en la recolección de la muestra, obteniendo un mejor resultado en el hisopo rectal que en las muestras de heces.

Por otro lado, en una investigación en la ciudad de Bari (Italia) entre el 15 de abril y 15 noviembre del 2010, donde se examinaron un total de 152 muestras fecales caninas y 66 muestras fecales de paloma doméstica no se logró aislar Salmonella, esto puede deberse al mayor control sanitario que existe en los países del primer mundo a diferencia de Latinoamérica (21).
Otro estudio realizado en Ecuador reportó una prevalencia mayor (12,5\%) al muestrear heces de perros en Yaruquí-Quito (16). En Nigeria, una investigación reportó una prevalencia del $43,7 \%$ de Salmonella spp. al analizar heces de perros callejeros (17). La diferencia entre las prevalencias de cada estudio se debe principalmente a la influencia de factores como: modo de muestreo, cantidad de muestras, métodos de aislamiento e identificación del microorganismo y el lugar de la toma de muestra.

El aislamiento de diferentes bacterias en una misma muestra suele ser muy común y se conoce como coinfección, que se evidenció en esta investigación. Duijvestijn et al, reportaron también uno o más agentes patógenos en el $86,5 \%$ de cachorros diarreicos y $77,8 \%$ de cachorros asintomáticos, los animales estuvieron infectados con uno, dos, tres y hasta cuatro patógenos, 29,2\%, $27,1 \%, 16,7 \%$ y $10,4 \%$ respectivamente. Entre estos se reportó Salmonella spp, Clostridium perfringens, Clostridium difficile, Escherichia coli -hemolítica, Campylobacter spp., virus y parásitos (22). En otro estudio donde se analizaron muestras de materia fecal de paloma doméstica de una ciudad de Costa Rica se reportaron coinfecciones ya que se logró aislar Salmonella entérica (24,1\%), Chlamydophila psittaci (9,2\%), Escherichia coli enteropatógena $(6,4 \%)$ y Campylobacter jejuni $(1,4 \%)(23)$.

En cuanto a las características macroscópicas, otros estudios también recalcan la importancia de determinar el tipo de muestra, como en la investigación de Cinquepalmi et al., donde analizaron 418 muestras fecales de perros (44\% muestras frescas y 56\% muestras envejecidas) aunque finalmente, no se logra aislar el patógeno 
(24). Por otro lado, en el caso de las palomas, existe un estudio realizado en Brasil reportan una prevalencia total de 7,94\% de 126 muestras fecales frescas y secas (25). Por lo tanto, ambos tipos de muestras son de alto riesgo de contaminación para los humanos en especial para personas inmunodeprimidas, ancianos, niños y mujeres embarazadas, debido a la larga supervivencia del patógeno en la materia fecal de los dos reservorios zoonóticos y en especial en el caso de las palomas que puede existir mayor diseminación de las heces por su vuelo migratorio. Finalmente, con respecto a la consistencia de las heces, el estudio de Westermarck et al., recalca la importancia de su determinación donde se afirma que los perros sanos tienen una prevalencia de 0 a $2 \%$, mientras que en los perros diarreicos puede llegar al $30 \%$ en el caso que sean alimentados con una dieta inapropiada de carnes crudas y existan otros factores insalubres (26). Por lo que, podría ser importante reportar la consistencia de la materia fecal, aunque también se conoce que la presencia de diarrea no es un signo clínico que indique que los animales padecen de enteritis causada por Salmonella spp. porque pueden ser portadores asintomáticos (19).

Entre las limitaciones de este estudio debemos considerar que en los resultados obtenidos no se determina el género, edad, alimentación y otras características que pueden influir en la microbiota de las heces de los animales analizados. Además, el uso de procesos automatizados y la inclusión de análisis por biología molecular pueden ayudar a identificar los serotipos de Salmonella circulantes y así establecer su verdadero potencial para causar enfermedades en humanos. Por otro lado, entre las fortalezas de este estudio está la contribución estadística y la determinación sobre el posible papel de las heces de perros y palomas como fómites para la diseminación de bacterias patógenas como Salmonella spp. Otra fortaleza es que en este estudio se analiza materia fecal de las dos especies zoonóticas de mayor presencia en parques y plazas de las ciudades, lo que implica un mayor contacto con la población que asiste a estos sitios.

En conclusión, los datos de prevalencia de Salmonella reportados en este estudio indican la existencia del microorganismo en la materia fecal de ambos reservorios zoonóticos y representan el primer paso para determinar un problema de salud pública. Por ello, es necesario que posteriormente se analicen que serovariedades fueron encontradas en este estudio para determinar el grado con el que afectan la salud del ser humano. Las muestras fecales de paloma doméstica tienen una prevalencia mayor que la de perros, lo que es alarmante porque son animales que recorren grandes distancias por su capacidad de volar, por lo que el microorganismo puede llegar a distribuirse más fácilmente. Es mandatorio establecer medidas de control y regulación de estos animales en los lugares recreativos y muy transitados para evitar la adquisición de salmonelosis y otras enfermedades zoonóticas.

\section{Conflicto de intereses}

Los autores declaran de manera explícita, no tener conflictos de intereses que pudieren haber sesgado los resultados incluidos en el manuscrito.

\section{Agradecimientos y patrocinio}

Agradecemos a la Universidad Central del Ecuador, a la Facultad de Ciencias Químicas y a su Área de Microbiología. 


\section{Referencias}

1. Organización Mundial de la Salud. Salmonella (no tifoidea) [Internet]. 2018 [cited 2019 Apr 27]. Available from: https://www.who.int/es/newsroom/fact-sheets/detail/salmonella-(nontyphoidal)

2. Organización Mundial de la Salud. Zoonosis y medio ambiente [Internet]. World Health Organization; 2015 [cited 2019 Apr 26]. Available from: https://www.who.int/foodsafety/areas_work/zoon ose/es/

3. Organización Panamericana de la Salud. Mortalidad en la región de las Américas [Internet]. 2017 [cited 2019 Apr 27]. Available from: https://www.paho.org/salud-en-lasamericas-2017/?post_t_es=mortalidad-en-laregion-de-las-americas\&lang=es

4. Ministerio de Salud Pública del Ecuador. Programa de control de la zoonosis [Internet]. 2008 [cited 2019 Apr 27]. Available from: http://instituciones.msp.gob.ec/dps/losrios/index. php?option=com_content\&view $=$ article $\&$ id $=37$ \&Itemid $=95$

5. Gargiulo A, Russo T, Schettini R, Mallardo K, Calabria M, Menna L, et al. Occurrence of enteropathogenic bacteria in urban pigeons (Columba livia) in Italy. Vector-Borne Zoonotic Dis [Internet]. 2014;14(4):251-5. Available from: https://www.liebertpub.com/doi/10.1089/vbz.201 1.0943

6. Merck. Manual merck de veterinaria. Sexta. Kahn C, Line S, editors. Barcelona: Océano; 2007.

7. Murray P, Rosenthal K, Pfaller M. Microbiología médica [Internet]. Sexta. Barcelona: El Seiver; 2017 [cited 2019 Jul 15]. Available from: https://www.academia.edu/38755861/Microbiolo gía_médica._Murray_6ta_edición
8. Jawetz S, Melnick M, Adelberg A. Microbiología médica. 25a ed. León J de, editor. Mc Graw Hill; 2010.

9. Asociación Empresarial Española de la Industria de Sanidad y Nutrición Animal. La industria de sanidad animal protagonista de la lucha contra las zoonosis [Internet]. 2015 [cited 2019 Jul 16]. Available from: http://www.veterindustria.com/key/noticias/laindustria-de-sanidad-animal-protagonista-de-lalucha-contra-las-

zoonosis_13564_4_13405_0_1_in.html\#lightbox $[13564] / 0 /$

10. Servicio Nacional de Sanidad Animal. Recomendaciones de Senasa para prevenir enfermedades en zonas inundadas [Internet]. 2016 [cited 2019 Apr 27]. Available from: https://www.agrositio.com.ar/noticia/180382recomendaciones-senasa-para-prevenirenfermedades-en-zonas-inundadas

11. Barba E. Estimación poblacional de perros callejeros en 20 sectores censales del sur de Quito por medio de un muestreo censal con el método captura y recaptura. Univ las Américas. 2017;86.

12. Quiguango D. Determinacion de la presencia de parasitos externos en palomas de Castilla (columba livia) en la ciudad de Quito, tomando como referencia tres lugares pilotos " $\mathrm{La}$ Magdalena", "Plaza de San Francisco" y "Cotocollao." Univ Cent Ecuador Fac Med Vet y Zootec [Internet]. 2015;44. Available from: http://www.dspace.uce.edu.ec/handle/25000/696 7

13. Ministerio de Salud del Perú. Manual para la vigilancia prevención y control sanitario de agentes zoonóticos y zoonosis relacionados a la paloma doméstica [Internet]. Perú; 2015 [cited 2019 Apr 27]. Available from: http://www.digesa.minsa.gob.pe 
14. Ministerio de Agricultura de Chile. Instructivo técnico para la detección de Salmonella spp. según ISO 6579:2002 [Internet]. 2015 [cited 2020 Oct 15]. Available from: http://www.sag.cl/sites/default/files/it-lab-26v02.pdf

15. Amadi VA, Hariharan H, Arya G, Matthew V, Nicholas R, Pinckney R, et al. Serovars and antimicrobial resistance of non-typhoidal Salmonella isolated from non-diarrhoeic dogs in Grenada, West Indies. Vet Med Sci [Internet]. 2018 Feb [cited 2019 Apr 28];4(1):26-34 Available from: http://www.ncbi.nlm.nih.gov/pubmed/29468078

16. Vasco K, Graham J, Trueba G. Detection of zoonotic Enteropathogens in children and domestic animals in a semirural community in Ecuador. Applied and environmental microbiology [Internet]. 2016 [cited 2019 Apr 28];82(14):4218-24. Available from: http://www.ncbi.nlm.nih.gov/pubmed/27208122

17. Jajere S, Onyilokwu S, Adamu N, Atsanda N, Saidu A, Adamu S, et al. Prevalence of Salmonella infection in dogs in Maiduguri, northeastern Nigeria. Int J Microbiol [Internet]. 2014 [cited 2019 Apr 28];2014:392548. Available from:

http://www.ncbi.nlm.nih.gov/pubmed/25404944

18. Oliveira M, Camargo B, Cunha M, Saidenberg A, Teixeira R, Matajira C, et al. Freeranging synanthropic birds (Ardea alba and Columba livia domestic) as carriers of Salmonella spp. and diarrheagenic Escherichia coli in the vicinity of an urban zoo. Vector-Borne Zoonotic Dis. 2017;18(1):65-9.

19. Gong J, Zhang J, Xu M, Zhu C, Yu Y, Liu $\mathrm{X}$, et al. Prevalence and fimbrial genotype distribution of poultry Salmonella isolates in China (2006 to 2012). Appl Environ Microbiol
[Internet]. 2014 Jan [cited 2019 Apr 28];80(2):687-93. Available from: http://www.ncbi.nlm.nih.gov/pubmed/24242234

20. Osman K, Mehrez M, Erfan A, Nayerah A. Salmonella enterica Isolated from Pigeon (Columba livia) in Egypt. Foodborne Pathog Dis. 2013;10(5):481-3.

21. Tarsitano E, Greco G, Decaro N, Nicassio F, Lucente M, Buonavoglia C, et al. Environmental monitoring and analysis of faecal contamination in an urban setting in the city of Bari (Apulia Region, Italy): health and hygiene implications. Int J Environ Res Public Health [Internet]. 2010 [cited 2019 May 11];7(11):3972. Available from: http://www.ncbi.nlm.nih.gov/pubmed/21139871

22. Duijvestijn M, Mughini L, Schuurman N, Schijf W, Wagenaar J, Egberink H. Enteropathogen infections in canine puppies: occurrence, clinical relevance and risk factors. Vet Microbiol [Internet]. 2016 Nov 15 [cited 2019 Apr 28]; 195:115-22. Available from: https://www.sciencedirect.com/science/article/pii /S0378113516303492?via\%3Dihub

23. Torres A, Blanco K, Rodríguez C, Duarte F, Jiménez M, Esperón F. Zoonotic agents in feral pigeons (Columba livia) from Costa Rica: possible improvements to diminish contagion risks. Vector-Borne Zoonotic Dis. 2017;18(1):49-54.

24. Cinquepalmi V, Monno R, Fumarola L, Ventrella G, Calia C, Greco $M$, et al. Environmental contamination by dog's faeces: a public health problem? Int J Environ Res Public Health [Internet]. 2012 Dec 24 [cited 2019 Apr 28];10(1):72-84. Available from: http://www.ncbi.nlm.nih.gov/pubmed/23263659

25. Sousa E, Júnior A, Pinto A, Machado R, Carrasco A, Marciano J, et al. Prevalence of 
Química Central (2021) Vol. 7 Núm. 1

Salmonella spp. antibodies to Toxoplasma gondii, and newcastle disease virus in feral pigeons (Columba livia) in the city of Jaboticabal, Brazil.

J Zoo Wildl Med. 2010;41(4):603-7.

26. Westermarck E. Chronic diarrhea in dogs: what do we actually know about it? Top Companion Anim Med [Internet]. 2016;31(2):78-84. Available from: http://dx.doi.org/10.1053/j.tcam.2016.03.00 